\title{
Influência do escore de condição corporal no eritrograma de vacas da raça Holandesa durante o puerpério e na fase pós-puerperal
}

Renan Braga Paiano $0^{[a]}$, Fábio Carvalho Lahr ${ }^{[b]}$, Daniela Becker Birge ${ }^{[b]}$, Eduardo Harry Birgel Junior ${ }^{[b]^{*}}$

\begin{abstract}
[a] Departamento de Anatomia dos Animais Domésticos e Silvestres, Faculdade de Medicina Veterinária e Zootecnia, Universidade de São Paulo (USP), Pirassununga, SP, Brasil

[b] Departamento de Medicina Veterinária, Faculdade de Zootecnia e Engenharia de Alimentos, Universidade de São Paulo (USP), Pirassununga, SP, Brasil
\end{abstract}

*Autor correspondente

e-mail: ehbirgel@usp.br

\section{Resumo}

A presente pesquisa teve o objetivo de avaliar se a perda de escore de condição corporal nos últimos 21 dias de gestação tem influência sobre o eritrograma de vacas holandesas durante o pós-parto. Foram utilizadas 25 vacas, da raça Holandesa, oriundas de rebanho pertencente a Prefeitura do Campus da Universidade de São Paulo Fernando Costa, localizado na cidade de Pirassununga, entre maio de 2015 e junho de 2016. Durante o pré-parto (21 antes do parto até o momento do parto) foi avaliado o ECC de todos os animais. Os animais foram alocados em 3 grupos: perda de ECC $=0$ (animais que não perderam escore corporal), perda de ECC $=0,25$ ou 0,50 (animais que perderam 0,25 ou 0,50 ponto de escore corporal nos últimos 21 dias de gestação) e perda ECC $=0,75$ (animais que perderam 0,75 ponto de escore corporal nos últimos 21 dias de gestação). Foram colhidas amostras de sangue da veia coccígea para o acompanhamento do hemograma nos seguintes momentos: imediatamente após o parto, 1, 7, 14, 21, 30, 45 e 60 dias após o parto. As amostras para hematimetria foram colhidas em tubos de vidro siliconizados contendo 0,05 ml de uma solução aquosa de etilenodiamino-tetracética-dissódica a 10\% e com vácuo suficiente para aspirar $5 \mathrm{ml}$ de sangue. O número de hemácias, o hematócrito, e a taxa de hemoglobina, assim como os índices hematimétricos absolutos foram mensuradas pelo contador automatizado BC-2800 Vet Mindray ${ }^{\circledR}$. No momento do parto os valores médios para o número de hemácias (ECC $=0-6,25 \times 10^{6} / \mathrm{mm}^{3}$, ECC $=0,25$ ou 0,50 - 6,19 X $10^{6} / \mathrm{mm}^{3} ; \mathrm{ECC}=0,75-6,04 \times 10^{6} / \mathrm{mm}^{3}$ ), para a taxa de hemoglobina $(\mathrm{ECC}=0-10,19 \mathrm{~g} / \mathrm{dL}, \mathrm{ECC}=0,25 \mathrm{ou}$ $0,50-10,30 \mathrm{~g} / \mathrm{dL} ; \mathrm{ECC}=0,75-10,11 \mathrm{~g} / \mathrm{dL})$ e para o volume globular $(\mathrm{ECC}=0-32,75 \% \mathrm{~g} / \mathrm{dL}, \mathrm{ECC}=0,25$ ou $0,50-32,52 \%$; $\mathrm{ECC}=0,75-32,06 \%$ ) foram muito semelhantes entre os três grupos. Nos primeiros 30 
dias pós-parto, observou-se uma redução gradativa no número de hemácias, taxa de hemoglobina e volume globular, entretanto, não foram observadas diferenças significativas entre os grupos experimentais. Nas amostras de sangue colhidas com 30 dias após o parto obteve-se os seguintes valores médios: ECC = 0 -

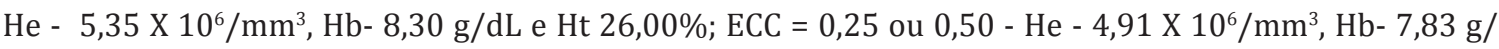
dL, Ht - 24,50\%; ECC = 0,75 - He - 4,99 X 10\% $/ \mathrm{mm}^{3}, \mathrm{Hb}-8,13 \mathrm{~g} / \mathrm{dL}$; Ht - 25,43\%. A partir de 30 dias após o parto houve a gradual recuperação dos valores do eritrograma em todos os grupos avaliados. Durante todo o experimento não foram observadas variações significativas nos índices hematimétricos absolutos. Apesar de existir um número significativo de animais anêmicos entre 21 e 30 dias pós-parto (32 \% dos 25 animais examinados), os resultados da presente pesquisa não evidenciaram relação entre a perda de escore corporal nos últimos 21 dias de gestação e a ocorrência de anemia durante o puerpério, pois durante todo o estudo não foram vistas diferenças nos valores de hemácias, hemoglobina e volume globular após o parto entre os grupos experimentais. 